\title{
Relaciones entre Provincia y Estado en el aspecto orgánico (*)
}

\author{
por \\ M. BAENA DEL ALCAZAR
}

SUMARIO: I. Introducción: 1. Generalidades. 2. Planteamiento del problema.II. La integración del Gobernador civil en la Diputación provincial: 1. La explicación histórica. 2. Las posiciones cioctrinales. 3. La interpenetración de las organizaciones central y local: A) La teoría de la tutela. B) Subordinación, coordinación e integración.-III. Posibilidades derivadas de la integración: 1. Administración central desconcentrada y Administración provincial. La Comisión Provincial de Servicios Técnicos. 2. La colaboración entre el Estado y la Provincia como ente local.

\section{INTRODUCCION}

\section{Generalidades.}

Bajo el título de relaciones entre Provincia y Estado pueden tratarse temas tan diversos, gracias a la amplia problemática que el enunciado sugiere, que bien merece la pena explicar el significado del título efectuando al mismo tiempo una delimitación inicial de nuestro estudio.

Desde luego, no se pretende aquí, en modo alguno, plantear ni intentar resolver, desde un enfoque y una perspectiva generales, el problema de las relaciones entre Administración central y local. Esto supondría tanto como enfrentarse desde el primer mo-

(*) El presente artículo reproduce de un modo prácticamente íntegro el texto de la comunicación presentada por el autor a la I Semana Internacional de la Provincia que, organizada por el Instituto de Ciencias Sociales de la Diputación provincial, tuvo lugar en Barcelona en los días 23 a 27 de noviembre de 1965. 
mento con las funciones a realizar por ambas Administraciones, cuestión complicada que la legislación española envenena más que regula, y en la que se pone en juego nada menos que la misma existencia de los entes locales como personas jurídicas o, al menos, la justificación de esta existencia. Aunque se espera que las páginas siguientes contribuyan en alguna medida a esclarecer el panorama jurídico español, se abordará desde una perspectiva distinta.

Por otra parte, como indica el título del trabajo, éste se circunscribe al examen de la situación de la Provincia y, por tanto, quedan fuera de las reflexiones presentes los problemas municipales. $Y$ ello no sólo por imposición de una exigencia inicial, sino también porque la peculiaridad del estudio es característica de la Provincia no presentándose en el caso del Municipio donde ni se superpone normalmente una Administración central desconcentrada a la actividad del ente menor, ni el Alcalde, en su calidad de órgano del Poder central, es al mismo tiempo jefe de los servicios centrales.

El tema se circunscribe por tanto, por supuesto dentro de la situación española, al examen de las relaciones entre la Administración estatal y la Provincia como persona jurídica, desde el punto de vista de las conexiones orgánicas que articulan ambos entes.

\section{Planteamiento del problema.}

Como es sabido, la Provincia tiene un doble carácter en el Derecho español, como se desprende de lo dispuesto en el artículis 2.o de la Ley de Régimen local: «La Provincia es circunscripción determinada por la agrupación de Municipios a la vez que división territorial de carácter unitario para el ejercicio de la competencia del Gobierno nacional».

Existe, por tanto, una Provincia, que no $\in \mathbb{S}$ más que una circunscripción territorial definidora de la competencia de unos servicios estatales. En definitiva esta acepción es la que corresponde a la tradición histórica (no demasiado clara tampoco en España antes de 1808) y a la carga conceptual aneja al sentido etimoló- 
gico del término. A este sentido se refiere el artículo 204 de la Ley al considerarla como circunscripción administrativa intermedia entre los Municipios y el Estado. Pero por otra parte existe una Provincia persona jurídica pública de carácter territorial (1) que se integra en la variada constelación de entes menores que, junto a la central, forman la llamada Administración indirecta.

Desde luego, a pesar de que la doctrina no ha dudado nunca de la personalidad de la Provincia como ente con sustantividad propia (2), lo cierto es que la Ley de Régimen local no se pronuncia con demasiada claridad sobre el tema. En el sentido de la consideración como persona jurídica hay que interpretar el artículo 6. de la Ley que otorga capacidad (y no personalidad) a las Diputaciones en cuanto que son representantes legales de la Provincia según el artículo 4.; y así hay que entender, desde luego, el artículo 406 que, a propósito de la responsabilidad, se refiere a una actuación de Derecho público y otra de Derecho privado. Sin embargo, una declaración tajante y rotunda no se encuentra en la Ley de Régimen local, existiendo en cambio en el artículo 1. de la Ley de la Jurisdicción contenciosa que, al considerar como Administración pública en su párrafo 2 a los entes que integran la Administración local, es claro que comprende entre ellos la Provincia.

Esta escasa claridad de la Ley de Régimen local no ha dejado de tener repercusiones en orden a un entendimiento claro del texto, porque lo cierto es que la Ley emplea a veces el término Provincia de una manera equívoca que no se sabe a cuál de las dos acepciones responde; ejemplo que ha cundido en la legislación española $\mathrm{y}$ del que se han aprovechado disposiciones posteriores como se verá más abajo.

La indefinición a que se viene aludiendo nos importa ahora porque en cierto modo también repercute en el aspecto orgánico. Según el artículo 211 de la Ley son órganos de gobierno y admi-

(1) De entre la numerosa bibllografia sobre la Provincia cabe destacar como obra más reclente la monografía de Vallina, V.: La Provincia, entidad local en España. Imprenta del Boletín Oficial de la Provincia. Oviedo, 1964. V. la bibliografía allí indicada, en especial en pág. 55.

(2) V. por todas la calificación de GARRIDo: Tratado de Derecho administrativo, I, 3.` ed., I. E. P. Madrid, 1964, pág. 319. 
nistración de la Provincia, cada uno con las atribuciones que la misma Ley les señala, el Gobernador civil, la Diputación provincial, el Presidente de la Diputación y la Comisión Provincial de Servicios Técnicos. No existe problema alguno respecto a la Diputación, representante legal de la Provincia según hemos visto disponía el artículo 4.ำ ni con el Presidente de la Diputación, figura que tanto ha contribuído a que la Administración provincial cobre definitivamente un perfil propio, como ha subrayado acertadamente García de ENTERría (3). Pero en cambio sí existe problema respecto a la Comisión Provincial de Servicios Técnicos (aunque por el momento no vamos a referirnos a ella por lo confuso de su situación que se trata de esclarecer más abajo) y sobre todo respecto al Gobernador civil. Es indudable que este último, a tenor del artículo 212 de la Ley, es el representante del Gobierno y Delegado permanente del Poder central, y también resulta incuestionable su calificación jurídica como órgano de la Administración central o directa debiendo interpretarse en este sentido el artículo 213 que se refiere a la dependencia directa del Ministerio de la Gobernación.

Pero antes de entrar en esta problemática debemos tener en cuenta para un planteamiento más correcto lo dispuesto en el artículo 220: «La administración de los intereses peculiares de la Provincia estará a cargo de la Diputación provincial y su Presidente, una y otro con atribuciones propias». A simple vista puede observarse la consecuencia: el Gobernador civil no está comprendido en la enumeración de los órganos administradores de los intereses peculiares de la Provincia. El Gobernador civil (4) según esto es simplemente un órgano de la Administración central.

Pero aquí es cuando comienza el verdadero problema. Siguiendo la vieja técnica napoleónica de articulación del Estado y los entes locales, el artículo 266, que reproduce lo dispuesto en la Base 37 de la Ley de 17 de julio de 1945, establece: «El Gober-

(3) García de ENTERría: «La Provincia en el régimen local español», en Problemas actuales de régimen local. Instituto García Oviedo, Sevilla, 1958, página 26.

(4) Nótese bien que, ateniéndose sólo al texto de la Ley, estas consideraciones no serian válidas para la Comisión Provincial de Servicios Técnicos que se consideraba como órgano de la Diputación. 
nador civil es Presidente nato de la Diputación provincial y en tal concepto le corresponde presidir con voto la Diputación y la Comisión Provincial de Servicios Técnicos cuando asista a sus sesiones pudiendo convocarlas con carácter extraordinario».

Nos encontramos aquí con este carácter del Gobernador como Presidente de la Diputación que lo sitúa a caballo entre la Administración central y la local. Desde luego esta conexión, herencia o imitación del Derecho francés, no es en absoluto una novedad. Es una cuestión vieja que se plantea con un enfoque nuevo. Se trata de averiguar qué significa esta conexión orgánica y de preguntarse qué posibilidades ofrece en la situación actual de nuestro Derecho local este viejo cauce de la actividad de los Gobernadores civiles, hoy desplazado por la deformada figura de la Comisión Provincial de Servicios Técnicos.

\section{LA INTEGRACION DEL GOBERNADOR CTVIL EN LA DIPUTACION PROVINCLAL}

En este apartado se pretende resolver el nudo de la cuestión planteada, esto es, la calificación jurídica de la integración del Gobernador civil en la Diputación provincial. Sin embargo, como datos indispensables, se hace preciso examinar primero la evolución histórica de nuestro régimen local respecto a este punto concreto así como las opiniones doctrinales sobre el tema.

\section{LA EXPLICACIÓN HISTÓRICA.}

En su estudio sobre La Provincia en el régimen local espanol (5) recuerda GARCÍA DE ENTERRÍA que como tantos temas de nuestra historia administrativa, la historia de nuestra Provincia, que no es la historia de la legislación sobre tal materia, está por hacer. Tampoco se intenta aquí, ni remotamente, hacerla, sino, simplemente, recordar algunos datos que proporcionen una perspectiva correcta.

Sabido es que la Provincia de la Edad Contemporánea aparece en España, o al menos cobra verdadera realidad, con la divi-

(5) En Problemas actuales de régimen,local, cit., pág. 12. 
sión territorial que realiza JAVIER DE BuRgos en 1833. En esta fecha, y durante muchos años después, la Provincia se concibe únicamente como pura circunscripción administrativa y los representantes del Gobierno en ella son, desde luego, órganos de la Administración central, siendo muy expresiva de su carácter subordinado la denominación primitiva de Subdelegados de Fomento. Sabida es también la noble idea que se hace JAvIER DE BURGos de estos que después deberían llamarse Gobernadores civiles, así como el triste papel de amañadores de elecciones que con expresiones felices describe GARCIA DE ENTERRÍA (6).

La aparición de la Provincia como ente local no se produce en realidad hasta que las Leyes de 1870 y 1876, desarrollando lo dispuesto en las Constituciones de 1869 y 1876, establecen el principio de gobierno y administración de los intereses peculiares de las Provincias y los pueblos por las respectivas Corporaciones.

No obstante, la historia que aquí nos interesa comienza en realidad con la Ley de 29 de agosto de 1882 (7). En el artículo 28 de esta Ley encontramos enumeradas las facultades del Gobernador como jefe de la Administración provincial, desafortunada expresión que se presta a equívocos cuando la repiten los textos legales vigentes, aunque era perfectamente correcta entonces al existir una verdadera dependencia jerárquica (8) de las Diputaciones respecto al Gobernador civil. Este artículo 28 establece ya en su número 1. la facultad de «presidir con voto la Diputación provincial y la Comisión (provincial) cuando asista a sus sesiones». Esto era lógico dentro del sistema estando en consonancia con ello la facultad de suspender los acuerdos de la Corporación. Tampoco puede extrañar a la vista de ello la tercera de las facultades que interesa destacar, que era la atribuída al Gobernador por el artículo 56 de la Ley de 1882: abrir en nombre del Gobier-

(6) GARCía DE ENTERRÍa: La Administración española. I. E. P. Madrid, 1961, págs. 95 y sigs.

(7) Una exposición del tema bajo la vigencia de la Ley, que se limita a resumirla, pero que lo hace adecuadamente, en SANTAMARía de Paredes: Curso de Derecho administrativo, 7. ${ }^{\circ}$ ed. Madrid, 1911, págs. 167 y sigs.

(8) V. al respecto ALVAREZ GENDíN: Tratado de Derecho administrativo, II. Bosch. Barcelona, 1963, pág. 137. 
no la primera sesión celebrada en cada período por la Diputación provincial.

El carácter y las atribuciones del Gobernador civil quedaban pues perfectamente claras. Aparece como el jefe total de la entidad Provincia, como el jefe de la Administración provincial, y en consecuencia con ello preside la Diputación cuando asiste a sus sesiones, así como la Comisión permanente de la Diputación, nota esta última que no carece de significado, ya que la permanencia de la Comisión hacía que ésta se convirtiese en la vía lógica para la actuación del Gobernador civil.

Por el momento puede afirmarse que la Ley de 1882 ha sido el texto español de más larga duración en materia de régimen local, ya que estuvo vigente hasta la promulgación del Estatuto provincial de 20 de marzo de 1925. Como es sabido el Estatuto se inspira en un principio totalmente opuesto al de la legislación anterior: el de la máxima autonomía e independencia de la Provincia. En consecuencia se robustecen la Diputación provincial y su Presidente, de tal modo que las facultades del Gobernador civil se restringen al máximo y se convierten prácticamente en honorarias. La intención de impedir la influencia del Gobernador se manifiesta claramente en el artículo 92: «El Gobernador civil de la Provincia podrá abrir, en nombre del Gobierno, el primer período de sesiones plenarias de cada año. En tales casos ocupará la presidencia desde la cual podrá dirigir la palabra a la Corporación, si bien estará vedado a ésta deliberar ni adoptar acuerdos en su presencia».

La legislación vigente, es decir, la Ley de Régimen local y sus Reglamentos, tiene un carácter sincrético ya que, en cuanto a lo que nos ocupa ahora, ha mezclado elementos de la Ley de 1882 y del Estatuto de 1925. Veamos, en primer lugar, los elementos autonomistas que provienen del último texto citado. La Ley de Régimen local confía claramente a la Diputación provincial y a su Presidente la administración de los intereses peculiares de la Provincia. En este sentido se produce un robustecimiento de la figura del Presidente de la Diputación (9) que, en palabras de García

(9) V. Gabcía Oviedo-Martinez Useros: Derecho administrativo, II, 8." ed. E. I. S. A. Madrid, 1962, págs. 355 y sigs. 
DE ENTERría (10) contribuye a que la Administración provincial cobre un perfil propio. En contrapartida a esto puede decirse que la figura del Gobernador civil parece que como Presidente de la Diputación reviste un carácter honorario y aunque, como veremos inmediatamente, esto no es así, podrían hacérnoslo pensar algunos preceptos como, por ejemplo, el artículo 137 del Reglamento de Organización y Funcionamiento de las Corporaciones locales según el cual el Gobernador da posesión al Presidente de la Diputación y preside la Corporación en este acto.

Pero en realidad en la legislación de Régimen local son mucho más numerosos e importantes los elementos autoritarios y centralistas que provienen de la Ley de 1882. Aun dejando aparte la facultad de suspender los acuerdos de la Corporación, el Gobernador conserva importantes atribuciones. Así vemos que el apartado j) del artículo 270 considera obligatorio para la Diputación asesorar al Gobernador civil en asuntos provinciales, lo que no sería lógico en absoluto si existiese una separación. Por otra parte está perfectamente en la línea de la Ley de 1882 la consideración del Gobernador civil como «jefe de la Administración provincial», expresión que vuelve a emplear para mayor confusión el Decreto de Gobernadores de 10 de octubre de 1958 (11). Dentro de estos elementos tiene singular relieve la presidencia de la Diputación y de la Comisión Provincial de Servicios Técnicos otorgadas al Gobernador por la Base 37 de la Ley de 1945 y el artículo 266 de la Ley de Régimen local. Verdaderamente el precepto no puede explicarse si no es considerándolo como un elemento tomado de la Ley de 1882 y mantenido por inercia o afán centralizador en un sistema posterior y muy diferente.

El artículo que consideramos tiene dos facetas. De un lado la que se refiere a la presidencia de la. Diputación siendo éste uno de los casos de sustitución que deroga el principio de irrenunciabilidad de la competencia establecido por el artículo 4. de la Ley

(10) V. García de ENTERría: «La Provincia en el régimen local español», en Problemas actuales de régimen local. Instituto García Oviedo. Sevilla, 1958, pág. 26.

(11) Deliberadamente no hace comentarios sobre el tema ALvarez GENDiN : «El Decreto regulador de las atribuciones y deberes de los Gobernadores civiles», Revista de Administración Pública, núm. 27, Madrid, 1958, pág. 174. 
de Procedimiento administrativo. De esto nos vamos a ocupar principalmente como se ha dicho antes. La segunda faceta se refiere a la presidencia de la Comisión Provincial de Servicios Técnicos que es $\tan$ herencia de la Ley de 1882 como la presidencia de la Diputación. A la vista de este último venerable texto puede sospecharse, con fundamento, que la cacareada novedad de la Comisión no es tal novedad porque resulta lógico pensar que es simplemente la vieja Comisión de la Diputación en la que se han introducido representantes de servicios y delegaciones estatales y a la que se ha dado un nombre nuevo. Incluso la deformación posterior que trata de convertirla en un organismo a través del que actúa de una forma ágil el Gobernador, se parece un tanto a la situación anterior en la que este último actuaba a través de la Comisión permanente.

En resumen puede decirse que la Ley de Régimen local es muy poco original respecto al punto que nos ocupa. En las relaciones entre órgano estatal-Gobernador civil y órgano provincial-Diputación, toma elementos de las normas de 1882 y 1925, y elementos que no encajan en el sistema. La puesta en práctica de la legislación ha mostrado por una parte la fuerza expansiva del Gobernador civil que ha utilizado a la Comisión Provincial de Servicios Técnicos en su lucha con los servicios de la Administración central desconcentrada, ya que la Aủministración provincial no es enemigo peligroso. $\mathrm{Y}$ esto, por otra parte, ha hecho que se vea la facultad de presidir la Diputación como lo que es en realidad: un milagroso resto anacrónico de la situación del XIX que se ha llegado a considerar como honorario. Lo cual es tanto más cierto cuanto que el Gobernador aparece triplemente robustecido por su condición de representante del Poder central, su posibilidad de -manejo de la Comisión Provincial de Servicios Técnicos, y su cualidad de Jefe provincial del Movimiento.

\section{LAS POSICIONES DOCTRINALES.}

Veamos cómo se pronuncia la doctrina a propósito de la conexión orgánica que supone la facultad de presidir la Diputación 
que se atribuye al Gobernador (12). Aunque en general puede decirse que el problema no ha preocupado excesivamente, ya desde el primer momento la doctrina advirtió la vinculación que fue subrayada, a raíz de la promulgación de la Ley de Bases, por GaSCón Y MARÍN (13).

En un sector doctrinal predomina una postura crítica respecto a lo dispuesto en el artículo 266 de la Ley. Así MARqués CARBó (14), que subraya la facultad del Gobernador de sustituir al Presidente de la Diputación en sus atribuciones como Presidente del órgano colegiado (definidas en el apartado $a$ ) del artículo 258), afirma: «No estimamos en modo alguno acertada la medida de erigir al Gobernador en Presidente nato de la Diputación y puede producir confusiones y situaciones delicadas la otorgación de las facultades de voto y convocatoria». Por otra parte, Alvarez GENDíN (15) plantea correctamente la cuestión al afirmar que «la circunstancia de que presida el Gobernador puede proceder del hecho de que antes del Estatuto provincial se consideraba a la Diputación como órgano internedio en el orden jerárquico entre el Ayuntamiento y la Administración central, siendo entonces muy lógico que se atribuyese al Gobernador esta presidencia de la Diputación; pero dentro del régimen que establece la Ley de Bases, considerando a estas entidades como autónomas, no parece tan lógico». Aunque se está de acuerdo con Alvarez Gendín, no sólo en cuanto al origen del precepto, sino sobre todo en cuanto a la certera visión del problema, las posiciones expresadas se estiman útiles más respecto al planteamiento que respecto a la solución del mismo.

Un segundo sector doctrinal alude directamente al tema aunque parece soslayarlo otorgándole escasa importancia. Tal es, por

(12) Una referencia al artículo 266 de la Ley, aunque sin comentarios de interés, en Vallina, V.: La Provincia, entidad local en España. Imprenta del Boletín Oficial de la Provincia. Oviedo, 1964, pág. 61.

(13) GaSCON Y MARIN: Nueva organización provincial, REvista DE Es'TUDIOS DE LA VIDA LOCAL, núm. 22, 1945, pág. 586.

(14) MARqués CARBO: El Derecho local español, II, primera parte. Barcelona, 1957-1958, pág. 215.

(15) ALVAREZ GENDIN: Tratado general, de Derecho administrativo, II. Bosch. Barcelona, 1963, pág. 147. 
ejemplo, el caso de García de EnTerría (16), quien afirma que el Gobernador conserva una presidencia de la Corporación que es preciso entender como honoraria; y en el mismo sentido se pronuncia García Oviedo-Martínez Useros (17), quien después de hacer constar que el Gobernador preside la Diputación dice (en nota) que «en la práctica estas funciones son realmente honorarias».

No se puede estar de acuerdo con esta postura, que tiene una posible base en el artículo 137 del Reglamento de Organización y Funcionamiento de las Corporaciones locales, porque, a tenor del artículo 266, no puede mantenerse que la presidencia sea honoraria. Casi podría pensarse que la Ley ha salido al paso de esta interpretación al otorgar a los Gobernadores la posibilidad de votar, porque es claro que un Presidente que asiste a las deliberaciones y emite después su voto, no es en modo alguno un Presidente honorario. Otra cosa será que estas funciones se ejerciten o no en la práctica, pero esto no significa gran cosa, porque aun suponiendo que no se ejercitaran, cualquier Gobernador celoso de sus atribuciones puede hacer valer sus facultades de presidencia de la Diputación. Es preciso explicar esta presidencia y examinar las posibilidades que ofrece, que son muchas y se encuentran muy conectadas con el planteamiento de las funciones provinciales que hace el mismo García de Enterría (18).

Por último, merece la pena destacar la posición de ENTrena CuEsta (19), para quien el Gobernador civil tiene una doble naturaleza, como órgano periférico de la Administración central y como órgano local, si bien en este último sentido le corresponde sólo la presidencia de la Diputación tal como dispone el artículo 266. EnTrena realiza una calificación jurídica acertada, y en tal sentido su postura es muy útil para orientarnoz en la cuestión. que se plantea. Pero de todas formas se pretende dar un paso más:

(16) García de Enterría: «La Provincia en el régimen local español», en Problemas actuales de régimen local. Instituto García Oviedo, Sevilla, 1958, página 26.

(17) García Oviedo-Martinez Useros: Derecho administrativo, II, 8.8 edición. E. I. S. A. Madrid, 1962, pág. 360.

(18) Especialmente en $\mathrm{La}$ Administración española. Instituto de Estudios Políticos. Madrid, 1961, págs. 108 y sigs.

(19) Entrena Cuesta: Curso de Derecho administrativo. Tecnos, S. A. Madrid, 1965, págs. 364 y 367. 
y averiguar qué significa esta doble calidad de órgano en orden a las relaciones entre Provincia y Estado, así como las posibilidades que ofrece en cuanto a la interacción constante entre ambos entes para el logro de finalidades públicas a que en otro lugar se refiere el mismo ENTRENA (20).

\section{LA INTERPENETRACIÓN DE LAS ORGANIZACIONES CENTRAL Y LOCAL.}

Se trata ahora de enfrentarse ya directamente con el problema planteado y, por tanto, de dar una explicación jurídica de la doble calidad del Gobernador civil que se comporta al mismo tiempo como órgano de dos personas distintas. Como es lógico esto incide directamente sobre las relaciones entre las personas jurídicas que tradicionalmente se explicaban por medio de la teoria de la tutela. Veamos cómo juega ésta y si es capaz de dar una solución a la conexión orgánica.

\section{A) La teoria de la tutela.}

Según la teoría tradicional las relaciones entre Administración directa e indirecta consistían en la tutela ejercida por la primera sobre la segunda. Como es lógico este apartado se limita a las relaciones con la Administración local (21).

En realidad, la teoría de la tutela nunca ha llegado a tener una gran precisión, como puede verse por las definiciones siguientes. Para Garrido (22) la tutela es el nexo que liga Administración directa e indirecta del Estado. La definición tradicional se debe a.

(20) ENTRENA CuEsta: «Introducción al estudio de las relaciones entre la Administración central y la Administración local», en Problemas politicas de la Vida local, II. Instituto de Estudios Políticos. Madrid, 1962, páginas 140 y 141.

(21) Un estudio y crítica de la teoría de la tutela en su aplicación a los entes funcionalmente descentralizados en mi trabajo, «Los entes funcionalmente descentralizados y su relación con la Administración central», $R e$ vista de Administración Pública, núm. 44. Madrid, mayo-agosto 1964, páginas 59 y sigs.; en especial págs. 97 y sigs.

(22) GARRIDO FALLA: Administración indirecta del Estado y descentralización funcional. Instituto de Estudios de Administración Local. Madrid, 1950, pág. 121. 
MASPÉTIOL y LAROCQUE, para quienes la tutela es el conjunto de poderes limitados concedidos por la ley a una autoridad superior sobre los agentes descentralizados, y sobre sus actos, con el fin de proteger el interés general (23). Por su parte, EnTPenNa Cuesta, modificando levemente la definición de Dembourg, da una similar a la de MASPÉTIOL y LAROCQUe y considera la tutela como el conjunto de poderes limitados otorgados por la ley a un órgano administrativo para controlar la legalidad de los actos de un ente descentralizado y su adecuación al interés general (24).

A pesar de estas aportaciones el concepto continúa siendo vago e indeterminado, así como el vocablo que se emplea para expresarlo, cuya inadecuación ha puesto de relieve la doctrina (25). La definición de GaRrIDo es, en definitiva, de carácter descriptivo y genérico y, por tanto, aunque proporciona una orientación general no precisa en el grado que nos resulta necesario en este momento. En cuanto a las otras definiciones, aun siendo las más exactas que ha dado la doctrina, muestran un inconveniente grave y muy significativo para este trabajo: no se incluye ni plantea dentro de la problemática del concepto la cuestión de las conexiones orgánicas entre las personas jurídicas. Esto es precisamente lo que induce a creer que en el actual grado de elaboración científica de la materia la idea de tutela es un simple concepto genérico en cuanto que engloba indistintamente las relaciones con la Administración local e institucional, y en cuanto que no proporciona orientación decisiva respecto a las facultades de la Administra-

(23) MASPETIOL y LAROCQUe: La tutelle administrative. París, 1930, página 10.

(24) ENTRENa Cuesta: \&Introducción al estudio de las relaciones entre la Administración central y la Administración local», en Problemas politicos de la Vida local, II. Instituto de Estudios Políticos. Madrid, 1962, pág. 138. A su vez esta definición difiere levemente de otra dada por el mismo ENTRENA con anterioridad: «Conjunto de poderes otorgados por la Ley a un órgano administrativo sobre los actos realizados por entes públicos descentralizados para asegurar la legalidad de tales actos y proteger los intereses cuya gestíón tiene encomendados el 6rgano de que se trate». Los movimientos centralizadores en Inglaterra. Instituto de Estudios de Administración Local. Madrid, 1960, pág. 129.

(25) V. al respecto.mi estudio citado «Los entes funcionalmente descentralizados y su relación con la Administración central», Revista de Administración Pública, núm. 44. Madrid, mayo-agosto 1964, págs. 97 y sigs., y la. bibliografía all indicada. 
ción directa y sus conexiones orgánicas con la indirecta y, en este caso, con la local.

La primera vía útil en orden a la solución que se busca está en un planteamiento de Garrmo Falla (26), que distinguía entre tutela sobre la organización y tutela sobre la actividad. Esta distinción, llevándola a sus últimas consecuencias lógicas, supone un giro de ciento ochenta grados respecto a la perspectiva tradicional, porque en vez de plantear el problema de las relaciones viendo a las dos personas jurídicas como dos bloques separados e independientes, podemos, siguiendo esta línea, enfocar las relaciones desde el punto de vista de interpenetración de las personas. $Y$ este punto de vista resulta muy útil en el caso de las relaciones entre Administración directa y Provincia, donde existe una superposición de situaciones, porque si bien es cierto que en muchos casos juega el punto de vista tradicional manifestándose en la necesidad de autorizaciones y aprobaciones para que la Provincia realice ciertos actos administrativos, no lo es menos que, junto a esto, se da la inserción del órgano estatal en el órgano local, cuyo estudio es objeto de este trabajo. La teoría de la tutela, concebida al modo tradicional, es suficiente para explicar el primer supuesto, pero resulta inútil para dar una explicación satisfactoria del segundo.

\section{B) Subordinación, coordinación e integración.}

En cuanto al tratamiento del tema de las relaciones enire Estado y entes locales se ha hecho recientemente una importante propuesta doctrinal. ENTRENA CuEsta, rompiendo en cierto modo con el esquema tradicional, adopta una perspectiva más amplia y clasifica las relaciones afirmando que pueden ser de subordinación y de coordinación (27). Las relaciones de subordinación engloban un control jerárquico y un control de tutela en el sentido

(26) GARRIDO FALLA: Administración indirecta del Estado $y$ descentralización funcional. Instituto de Estudios de Administración Local. Madrid, 1950, págs. 184 y sigs.

(27) ENTRENA CUESTA: «Introducción al estudio de las relaciones entre Administración central y Administración local», en Problemas politicos de la Vida local, II. Instituto de Estudios Políticos. Madrid, 1962, pág. 137. 
tradicional (28), dándose el control jerárquico cuando los entes locales ejercen funciones estatales, ya que para ENTRENA en estos casos actúan como órganos de la Administración central, siendo aplicable el artículo 1.9 de la Ley de Régimen jurídico de la Administración del Estado (29). Las relaciones de coordinación se dan, en cambio, cuando existe una colaboración o una cooperación de uno de los entes al cumplimiento de funciones de otro (30). $\mathrm{Pa}$ rece ser que ENTRENA califica jurídicamente una realidad, pero no está muy satisfecho de ella, puesto que afirma que las relaciones de subordinación, que se circunscriben al ámbito de la organización administrativa, son insuficientes para conseguir una adecuación de las actividades de los entes públicos menores de carácter territorial al interés general; mientras que por otra parte dice que las relaciones de coordinación deben considerarse como una manifestación de las deficiencias existentes en la actual organización administrativa que debe ser modificada adaptándola a los problemas y las técnicas que plantea y de que dispone una Administración moderna (31).

En otras ocasiones la doctrina se había referido ya a nuestro objeto de estudio mostrándose poco de acuerdo con la situación actual. Así García de ENTERRía (32), no sintiéndose satisfecho con la gestión de servicios estatales a nivel provincial apela al ejemplo de las entidades estatales autónomas que según el artículo 1.ㅇ de su Ley reguladora prestan servicios estatales, y se refiere a la instrumentalidad de estos entes, aludiendo a la calificación de OTTAViANo para añadir a continuación que «no se ve entonces dónde puede radicar el obstáculo para aplicar a las relaciones entre el Estado y los entes locales una fórmula análoga de articulación». Por otra parte, MARQUÉS CARBó (33), precisamente al criticar la posibilidad de que el Gobernador presida la Diputación, formula un juicio acertado sobre este punto al decir que esta situación es

(28) Entrena, ob. cit., pág. 138.

(29) Entrena, ob. cit., pág. 127.

(30) ENTRENA, ob. cit., págs. 138-139.

(31) Entrena, ob. cit., pág. 141.

(32) García DE ENTERRIA: La Administración española. Instituto de Estudios Políticos. Madrid, 1961, págs. 160 y 161.

(33) MARqués CARBó: El Derecho local español, II, primera parte. Barcelona, 1957-1958, pág. 215. 
una consecuencia de conceptuar a los entes locales como insertados en el Estado y cooperadores a los fines del Estado.

Todo esto significa que la doctrina tiene conciencia de que la Provincia depende muchas veces del Estado de una manera total (34), mientras que otras actúa en colaboración con él, lo que resulta lógico si la Administración provincial es Administración del Estado aunque sea indirecta. Pero ¿cómo se explica esta situación desde el punto de vista orgánico? La respuesta no puecie ser más que una: a través de la vía que ofrece el mencionado artículo 266 posibilitando la inserción del órgano de la Administración central en la Diputación provincial.

En la situación actual esta posibilidad no es tan nefasta como parece creer MARQUÉS CARBó. Por otra parte, a pesar de la conexión orgánica que supone no puede hablarse en este caso de instrumentalidad a no ser utilizando una analogía muy remota. La instrumentalidad puede predicarse de los entes funcionalmente descentralizados, y no tanto de éstos cuanto de su integración en la organización estatal, porque en este caso la personalidad opera como principio de organización (35) para conseguir la creación de un ordenamiento singular $y$, en virtud de ello, los entes funcionalmente descentralizados se integran en la Administración estatal de un modo paralelo a los órganos (36). Pero como bien dice GUARINo (37), las relaciones dependen de la naturaleza de la actividad del ente y no cabe duda que esta actividad es muy distinta en el

(34) Un ejemplo claro de ello lo constituye el artículo 381 de la Ley de Régimen local: «Las cuestiones que se produzcan sobre incapacidades, excusas o incompatibilidades de los miembros de las Corporaciones locales serán resueltas por los Gobernadores civiles y contra su resolución podrá recurrirse en alzada ante el Ministro de la Gobernación sin que quepa ulterior recurso». Comentando este precepto, González Pérez afirma que el aludido es un recurso de alzada impropio que tiene como fundamento la tutela. Los recursos administrativos. Instituto de Estudios Políticos. Madrid, 1960, pág. 130.

(35) V. Ottaviano: Considerazioni sugli enti pubblici strumentali. Milani, Padova, 1959, pág. 53.

(36) BAENA: «Los entes funcionalmente descentralizados y su relación con la Administración central», Revista de Administración Pública, núm. 44. Madrid, mayo-agosto 1964, págs. 117-118.

(37) GUaRINo: Scritti di Diritto pubblico dell'economia e Diritto dell'energia. Giuffrè. Milán, 1962, pág. 75. Precisamente por eso en mi trabajo anteriormente citado no se acepta la instrumentalidad sino después de un examen de la naturaleza de la actividad del ente. 
caso de la Provincia que en el de los entes funcionalmente descentralizados. En el caso de la Provincia el ente ha sido creado para gestionar intereses propios en primer lugar, aunque actualmente gestione también intereses estatales, mientras que los entes funcionalmente descentralizados gestionan exclusivamente intereses estatales. Pero es que, además, la Provincia, al menos tal y como viene regulada en la Ley de Régimen local, es decir, tal como la encontramos actualmente, no ostenta la personalidad jurídica para que ello posibilite la creación de un ordenamiento singular más flexible que el general, lo que sí sucede, en cambio, con los entes institucionales a que se acaba de aludir. En este caso no se trata de realizar funciones estatales de un modo más ágil y flexible, sino de gestionar intereses propios. El Estado no ha creado la persona jurídica Provincia para que le sirva de instrumento en orden a realizar fines propios.

Lo que no significa que no puedan aplicarse en alguna medida puntos de vista obtenidos en el estudio de la instrumentalidad, sino que hay que hacerlo con las debidas cautelas. Para ello resulta conveniente un replanteamiento del problema. De acuerdo con la Ley de Régimen local pueden presidir la Diputación provincial, órgano gestor de la Provincia, el Presidente de la Diputación propiamente dicho o el Gobernador civil cuando asista a sus sesiones. El Presidente de la Diputación no es un órgano estatal $\mathrm{y}$, por tanto, sus facultades no plantean problema siendo de presumir que cuando la Corporación delibere sobre los intereses peculiares de la Provincia el Gobernador no tiene por qué asumir la presidencia (38). En estas ocasiones el Gobernador puede, sin embargo, suspender los acuerdos ilegales, pero entonces actúa en el ejercicio de la tutela concebida al modo tradicional.

En cambio, cuando preside el Gobernador civil se da una integración del órgano central en el órgano local. Nos encontramos entonces en una situación inversa a la de los entes funcionalmen-

(38) Partiendo del punto de vista de que la presidencia del Gobernador no es honoraria, el fallo esencial de lo dispuesto en el artículo 266 de la Ley consiste justamente en que el Gobernador, si quiere, puede presidir la Corporación aun cuando ésta delibere sobre asuntos peculiarmente provinciales. En realidad, de lege ferenda, lo deseable seria que le estuviera vedado al Gobernador presidir la Diputación en estos casos. 
te descentralizados, porque mientras éstos se integran en la Administración central de un modo paralelo a los órganos, en el caso contemplado, inversamente, es el órgano central el que se inserta en el local en ciertas ocasiones asegurando de este modo la conexión entre las organizaciones de ambas personas jurídicas y convirtiendo así a la Provincia en verdadera Administración del Estado, aunque indirecta. Vemos, por tanto, que las relaciones entre Provincia y Estado en su aspecto jurídico pueden plantearse o como las existentes entre dos personas jurídicas separadas y distintas, interviniendo los órganos de la superior únicamente para homologar las decisiones de los órganos de la inferior; 0 como las que se dan entre personas jurídicas que incidentalmente pueden integrarse en una organización común, lo que se consigue a través de la facultad del Gobernador de sustituirse en las facultades que tiene el Presidente de la Diputación como tal Presidente del órgano colegiado que la Corporación constituye (39).

En resumen, puede decirse que la fórmula del artículo 266 de la Ley de Régimen local posibilita la existencia de una integración incidental de la Diputación provincial en el complejo orgánico de la Administración del Estado, integración que coexiste con la tutela concebida al modo tradicional. De esta manera, gracias a la facultad de sustitución conferida al Gobernador podría realizarse la gestión de intereses estatales sin que esto supusiera una anomalía. Esto explicaría la existencia de las relaciones de jerarquía

(39) Sobre la sustitución concebida como la que se realiza entre órganos de personas jurídicas distintas véase para el Derecho francés ViGNEs: «Le pouvoir de substitution», Revue de Droit Public et de la Science Politique, julio-agosto 1960. A propósito de este tema puede plantearse la cuestión de si es aplicable a la relación contemplada el principio del artículo 4.2 de la Ley de Procedimiento, según el cual la competencia es renunciable en los casos de sustitución previstos por la Ley, pudiendo basarse la duda en que la Ley de Procedimiento no es aplicable a los entes locales. Debe estimarse, por el contrario, que el artículo resulta aplicable, no sólo por tratarse de relaciones en las que uno de los sujetos forma parte de la Administración central, sino porque el sustituyente es, desde luego, un órgano de ésta. En la doctrina española Vallina, J. L., que hace un estudio general de la sustitución, afirma que tiene su fundamento en un estado patológico de la vida administrativa del sujeto sustituído, no contemplando el supuesto planteado en el texto. VALLINA: Transferencia de funciones administrativas. Instituto de Estudios de Administraction Local. Madrid, 1964, págs. 166 y sigs.; en especial págs. 170 y 171 y la bibliografía allí indicada. 
a que se refiere ENTRENA, que no sería posible de otro modo entre órganos de personas jurídicas distintas, así como podría suponer una coordinación asegurada y lógica entre ambas organizaciones a efectos de que la Provincia gestione intereses estatales. Esta conexión puede explicar también, en los casos en que afecte a la Provincia, la posibilidad de entablar recursos de alzada impropios contra las actuaciones de la Diputación, así como ciertas facultades de los Gobernadores como, por ejemplo, las del artículo 381 de la Ley. Por último explica también la atribución de la Diputación de asesorar al Gobernador en asuntos provinciales a que se refiere el artículo 270 de la Ley.

De todas formas es preciso insistir sobre un punto. Se ha dicho que la fórmula del artículo 266 abre una serie de posibilidades que no es lo mismo que afirmar que se lleven a la práctica. De hecho es potestativo del Gobernador el presidir la Diputación provincial y actuar de este modo en colaboración con la Provincia para gestionar intereses estatales. Parece ser que la necesidad de gestionar asuntos provinciales de interés estatal se ha resuelto por una vía distinta sin contar con esta posibilidad de conexión orgánica $\mathrm{y}$, en definitiva, en perjuicio de la importancia. $\mathrm{y}$ la vida de la Corporación provincial que ha visto arrastrada su competencia por órganos pura y exclusivamente estatales. Sin pretensiones de agotar la materia, en el resto del presente trabajo se repasa este proceso para utilizarlo como contraste a efectos de mostrar la utilidad potencial del artículo 266 del texto refundido de 24 de junio de 1955.

\section{POSIBILIDADES DERIVADAS DE LA INTEGRACTON}

1. AdMinistración CENTRAL DESCONCENTRAda Y ADministración provinctal. La Comisión Provinctal DE SERvicios Técnicos.

Es un hecho bien sabido que en España ha proliferado una Aảministración central desconcentrada constituída por una innumerable y variopinta pluralidad de Delegaciones regionales y pro- 
vinciales de los diversos Ministerios, Administración cuya actividad es inevitablemente competitiva de la de los entes locales como ha subrayado GarCía dE ENTERRía (40). Esta Administración, cuya justificación y oportunidad ofrece muchas dudas (41), ha desenvuelto en la mayoría de los casos una actividad al margen de la organización tradicional, lo que ha llevado como consecuencia que la vieja fuerza atractiva del Gobernador civil no actúe respecto a la Provincia y sus órganos gestores, sino respecto a este conjunto de Delegaciones. La manifestación de la reacción del Gobernador civil ha sido la aparición de ese organismo híbrido que es la Comisión Provincial de Servicios Técnicos (42) y el golpe decisivo que ha tratado de restablecer el dominio del Gobernador ha consistido en transformar la Comisión de la Ley de Régimen local en la que funciona a partir de la entrada en vigor del Decreto de 10 de octubre de 1958.

Esta Comisión, como se ha apuntado más arriba, tiene posiblemente su origen en la Comisión provincial de la Ley de 1882, pieza del sistema destinada a ser instrumento ágil y manejable en manos del Gobernador civil. Pero la realidad ha cambiado y ahora no es tan importante manejar a la Diputación cuanto a las Delegaciones provinciales y regionales de los Ministerios. El resultado ha sido que la Comisión, concebida en la Ley de Régimen local como un órgano integrado en la Diputación provincial que respondía al deseo de fomentar un encuentro entre Estado y Pro-

(40) García de ENTERRía: La Administración española. Instituto de Estudios Políticos. Madrid, 1961, pág. 144.

(41) V. García DE ENTERRÍa, ob. y loc. cit.

(42) En este sentido, García DE ENTERría, ob. cit., pág. 100. V. con carácter general respecto a la Comisión García DE ENTERRÍA: "Los planes provinciales de obras y servicios», en Problemas actuales de régimen local. Instituto García Oviedo. Sevilla, 1958, págs. 117 y sigs. Ortiz Díaz: «Unidad y coordinación de los órganos y servicios estatales a nivel provincial: el Decreto de 10 de octubre de 1958», REvisTa DE ESTUDios DE LA VIDA LOCAL, número 106, julio-agosto 1959, págs. 481 y sigs. LOBato BRIME: «La Comisión Provincial de Servicios Técnicos y los planes provinciales de obras y servicios», REviSTA DE ESTUdIOS DE LA VIDA LOCAL, núm. 113. Madrid, septiembre-octubre 1960, págs. 702 y sigs. MENdizábal Allende: «Naturaleza jurídica y encuadramiento orgánico de la Comisión Provincial de Servicios Técnicos», Revista de Administración Pública, núm. 41. Madrid, 1963, páginas 71 y sigs. 
vincia (43), a partir del Decreto de Gobernadores de 10 de octubre de 1958, y a pesar de lo dicho por su Exposición de Motivos (44), tiende a configurarse como un órgano estatal perdiendo toda dependencia respecto a la Diputación y convirtiendo en irrisoria no sólo la fórmula de la Ley de Régimen local, sino, incluso, la del artículo 52 del mismo Decreto en su segunda redacción publicada en el Boletin Oficial de 9 de diciembre de 1958 (45). La Comisión provincial ha vuelto a ser un instrumento en manos del Gobernador y la actividad de éste se ha desplazado dejando de actuar a través del cauce de los organismos provinciales con lo que éstos, necesitados hoy día de la cooperación constante del Estado, se han deslizado hacia una vía muerta.

A esto se ha unido otra circunstancia que ha llevado consigo un perjuicio definitivo para la actividad de la persona jurídica Provincia. El párrafo segundo del artículo 1. del Decreto de 13 de febrero de 1958 al especificar qué se entiende por obras o servicios de carácter eminentemente provincial, considera como ta-

(43) El entonces Ministro de la Gobernación PEREZ GONZÁlez, al presentar a las Cortes la Ley de Bases de 1945, afirmaba que mediante las Comisiones Provinciales de Servicios Técnicos se ensayaba un encuentro de la Diputación y los representantes en Provincias de los servicios centrales. Se perseguia con ello unir esfuerzos e intereses de Estado y Provincia y ausentar trabas de fronteras y competencias. $Y$ a rafz de la promulgación de la Ley de Bases la doctrina se hizo eco de estas intenciones. Asi, Gascon Y MARí afirmaba que al redactarse el articulado de la Ley se debería puntualizar el enlace de la Comision con los otros órganos provinciales y locales, así como con los del Estado. «Nueva organización provincial», REvisTa DE ESTUdios DE LA VIDA LOCAL, núm. 22, 1945, pág. 586.

(44) Esta Exposición de Motivos dice que las Comisiones Provinciales de Servicios Técnicos se crearon en la Ley de Régimen local para unir Estado y Provincia y que con tan laudable intento y saludable signo perduran en el Decreto como el órgano más adecuado para coordinar todos los servicios de la Provincia». Es claro que esto es rigurosamente inexacto y su única explicación razonable es el manejo equivoco del término Provincia, sin distinguir su calidad de ente local con personalidad jurídica y su carácter de circunscripción administrativa estatal. Por lo demás, como es sabido, la legalidad del Decreto ofrece serias dudas que esta «aclaracion» no puede disipar.

(45) En este sentido la Sentencia del Tribunal Supremo de 3 de julio de 1962 citada por MENDizÁBal ALlende, según la cual las Comisiones tienen una estructura incompatible con cualquier clase de subordinación a la Diputación provincial. «Naturaleza jurídica y encuadramiento orgánico de las Comisiones Provinciales de Servicios Técnicos», Revista de Administración Pública, núm. 41. Madrid, 1963, pág. 87. 
les, con descaro según la expresión de García de ENTERRÍA (46), los comprendidos en el artículo 243 de la Ley de Régimen local que es precisamente el que especifica los servicios de competencia de la Provincia. Es claro que después de esto el papel de la Diputación provincial y el de la Provincia como persona jurídica han quedado muy reducidos.

La consecuencia ha sido que la Comisión Provincial de Servicios Técnicos se ha arrogado una representación de la Provincia que no le pertenece en modo alguno (47) y se ha convertido por completo en un órgano estatal lo que es patente sobre todo a la vista del Decreto de 30 de enero de 1964 y la Orden de 25 de febrero del mismo año que les encomienda funciones en orden a la gestión de los polos de promoción y desarrollo industrial, y del Decreto de 11 de febrero de 1965 según el cual las resoluciones adoptadas respecto a estas materias podrán ser objeto de recurso de alzada ante la Presidencia del Gobierno (48).

La competencia atribuída a la Diputación por la Ley de Régimen local se ha transformado en algo vacío e inoperante. La Comisión Provincial de Servicios Técnicos, primitivamente de la Diputación, se ha convertido por completo en un órgano estatal y con tal carácter ha desarrollado una actividad competitiva llegando, incluso, a arrogarse una representación de la Provincia que carece de razón de ser. En estas circunstancias no es extraño que el cauce de colaboración entre Provincia y Estado constituído por

(46) García de ENTERRÍa: La Administración española. Instituto de Estudios Políticos. Madrid, 1961, pág. 142.

(47) Un curioso sintoma de ello es que según el Decreto de 10 de octubre de 1958 forman parte de las Comisiones los Procuradores en Cortes representantes de los Municipios de las Provincias respectivas. Es claro que esto no otorga a la Comisión carácter representativo de la Provincia, ya que según el artículo $4 .^{\circ}$ de la Ley de Régimen local, la representación legal corresponde a la Diputación.

(48) Al otorgar atribuciones a las Comisiones provinciales en orden a la gestión de los polos se ha olvidado por completo lo dispuesto en el artículo 6. -5 de la Ley que aprobaba el Plan según el cual el Estado procuraría la colaboración activa de la Provincla como unidad política y administrativa. Al menos se ha interpretado que se trataba de la circunscripción administrativa y no del ente local con personalidad juridica. V. respecto al tema MEILAN: «Observaciones acerca del régimen jurídico de los Polos de Promoción y Desarrollo», Documentación Administrativa, núm. 77, Madrid, mayo 1964, págs. 30 y sigs. 
la posible presidencia de la Diputación por parte del Gobernador civil haya llegado a considerarse como algo puramente honorario. Veamos ahora las posibilidades que ofrece en orden al problema de las funciones estatales y provinciales.

\section{La colaboración entre el Estado y la Provincia COMO ENTE LOCAL.}

Todo lo anterior conduce a una desorientación total basada en la confusión inicial entre las dos acepciones de la Provincia, que tras el proceso sumariamente descrito, ha conducido a un debilitamiento continuo de la Provincia y de la Diputación provincial. El interés de la fórmula del artículo 266 del que se ocupa este trabajo consiste en que, por obra del milagroso anacronismo que supone la supervivencia de la articulación napoleónica, ofrece una vía de solución a estos problemas.

De acuerdo con la Ley de Régimen local la Provincia debe estar representada por la Diputación provincial y, en buena lógica, deben encomendarse a ésta los servicios que gestiona la Administración periférica o al menos una parte de ellos. Por otra parte es preciso rechazar un provincialismo ingenuo y propugnar una colaboración entre la Provincia y el Estado. En nuestros días la Provincia desarrolla funciones estatales (49) y esto es inevitable porque, como subraya GarCía DE ENTERRÍA (50), no se puede construir el círculo de las competencias provinciales prescindiendo por completo del Estado. La Provincia desarrolla un conjunto de funciones que ENTRENA clasifica en propias, impropias, indistintas y mixtas (51) y salvo las primeras todas ellas han de ejercerse en colaboración con el Estado. Ahora bien, para esto debe existir una articulación entre las organizaciones de ambas personas jurídicas.

(49) En este sentido ENTRENA: «Introducción a las relaciones entre la Administración central y la Administración local», en Problemas políticos de la Vida local, II. Madrid, 1962, pág. 131.

(50) GARCí DE ENTERRIA : La Administración española. Instituto de Estudios Políticos. Madrid, 1961, pág. 108.

(51) Entrena, ob. cit., págs. 136-137. Las funciones impropias son las que en puridad corresponderian al Estado; las indistintas son las que pueden corresponder a cualquiera de los dos entes; las mixtas o compartidas las que están atribuídas simultáneamente al Estado y a la Provincia y deben ser ejercidas conjuntamente. 
La fórmula que se ofrece es la siguiente. Debería suprimirse la Comisión Provincial de Servicios Técnicos de una parte, y de otra delimitar claramente las funciones propias de la Provincia. Esta debe realizar por sí misma un núcleo de funciones propias, las que ejerce ahora, y la parte que se estimara conveniente atribuirle de las que gestiona la Comisión Provincial de Servicios Técnicos. Cuando la Diputación delibere sobre estas materias debe ser presidida por su Presidente, siendo conveniente que se prohiba al Gobernador la asistencia a las sesiones. En estos casos la Administración central debería limitar su intervención a la homologación de decisiones mediante la suspensión de acuerdos ilegales.

Por otra parte la Provincia debería gestionar o cooperar en la gestión de intereses estatales y en estos casos el Gobernador civil, haciendo uso de la facultad de sustitución que le confiere el artículo 266 de la Ley de Régimen local, actuaría como Presidente de la Corporación, dándose de este modo una integración incidental del órgano gestor de la Provincia en la organización total del Estado. De este modo operaría la Administración provincial como verdadera Administración del Estado, aunque siempre Administración indirecta. 